NBER WORKING PAPER SERIES

\title{
ECONOMIC CONDITIONS AND CHILDREN'S MENTAL HEALTH
}

\author{
Ezra Golberstein \\ Gilbert Gonzales \\ Ellen Meara \\ Working Paper 22459 \\ http://www.nber.org/papers/w22459 \\ NATIONAL BUREAU OF ECONOMIC RESEARCH \\ 1050 Massachusetts Avenue \\ Cambridge, MA 02138 \\ July 2016
}

This work is supported by a Grant-in-Aid from the University of Minnesota Office of the Vice President for Research and by the Minnesota Population Center grant from the Eunice Kennedy Shriver National Institute for Child Health and Human Development (5R24HD041023). We are grateful for helpful feedback from Padmaja Ayyagari, David Cutler, Christopher (Kitt) Carpenter, Daniel Eisenberg, and seminar participants at ASHEcon 2016, Cornell University, Johns Hopkins University, University of Minnesota, University of Wisconsin, Vanderbilt University and Yale University. We are especially grateful to Patricia Barnes of the National Center for Health Statistics for her assistance with accessing restricted National Health Interview Survey data. This research was conducted while the authors were Special Sworn Status researchers of the US Census Bureau at the Center for Economic Studies. Research results and conclusions expressed are those of the authors and do not necessarily reflect the views of the Census Bureau or the National Bureau of Economic Research.

NBER working papers are circulated for discussion and comment purposes. They have not been peer-reviewed or been subject to the review by the NBER Board of Directors that accompanies official NBER publications.

(C) 2016 by Ezra Golberstein, Gilbert Gonzales, and Ellen Meara. All rights reserved. Short sections of text, not to exceed two paragraphs, may be quoted without explicit permission provided that full credit, including ( $)$ notice, is given to the source. 
Economic Conditions and Children's Mental Health

Ezra Golberstein, Gilbert Gonzales, and Ellen Meara

NBER Working Paper No. 22459

July 2016

JEL No. I1

\begin{abstract}
$\underline{\text { ABSTRACT }}$
Research linking economic conditions and health largely ignores children's mental health problems, which are the most common and consequential health issues for children and adolescents. We examine the effects of unemployment rates and housing prices on child and adolescent mental health and use of special education services for emotional problems in the 2001-2013 National Health Interview Survey. Mental health status declines as economic conditions deteriorate, and this result is pervasive across nearly every subgroup we examine, including families least likely to experience job loss. The use of special education services for emotional problems also rises when economic conditions worsen.
\end{abstract}

\author{
Ezra Golberstein \\ Division of Health Policy and Management \\ University of Minnesota \\ School of Public Health \\ 420 Delaware St. SE, MMC 729 \\ Minneapolis, MN 55455 \\ egolber@umn.edu \\ Gilbert Gonzales \\ Department of Health Policy \\ Vanderbilt University \\ School of Medicine \\ 2525 West End Ave, 1200 \\ Nashville, TN 37203 \\ gilbert.gonzales@vanderbilt.edu
}

Ellen Meara

Dartmouth Institute for Health Policy

and Clinical Practice

35 Centerra Parkway

Lebanon, NH 03766

and NBER

ellen.r.meara@dartmouth.edu 


\section{Introduction}

How do economic downturns affect the health and well-being of children? Although an expansive literature links economic conditions and adult health, the relationship between the economy and children's health is largely ignored. In this paper, we examine the effect of economic conditions on the most prominent health issue among children: mental health. Mental health problems for children and adolescents are more common than physical health problems, and poor mental health impedes human capital accumulation and future labor market outcomes more than physical conditions (Case, Fertig et al. 2005, Currie, Stabile et al. 2010, Goodman, Joyce et al. 2011).

To begin to fill the gaps in our understanding of economic conditions and child health, we present the most comprehensive evidence to date on the effects of economic conditions on children’s and adolescents’ mental health. We link 13 years of nationally-representative data with measures of child mental health status and use of intensive services for emotional problems to two measures of economic conditions: unemployment rates and housing prices. We find that the effects of economic conditions on children's mental health are clinically and economically meaningful; children's mental health outcomes worsen as the economy weakens. The effects of economic conditions on child and adolescent mental health are pervasive, found in nearly every subgroup that we examine. Turning to possible mechanisms that link economic conditions to child mental health, parental unemployment cannot fully account for the relationship between child mental health and economic conditions. Rather, we hypothesize that other mechanisms like reduced family income and increased levels of family stress associated with recessions are likely to influence child mental health. 
Aside from gaining new insight into the production of children's mental health, our results are important for two reasons: (1) our study documents an important spillover effect of recessions on individuals outside the labor market, creating potentially long term consequences for labor supply and the economy; and (2) we document counter-cyclical demand for an important and costly, publicly-financed service, special education for emotional problems. The

remainder of the paper proceeds as follows: section 2 provides background on mental health problems in childhood and adolescence; section 3 describes the potential mechanisms that explain how economic conditions affect children’s mental health, and the relevant existing empirical work; section 4 describes our data and empirical approach; section 5 contains our results; and section 6 concludes.

\section{Background on Economic Conditions and Children's Mental Health}

An extensive literature examines the effects of economic conditions on health. Seminal work by Ruhm demonstrated that mortality rates are procyclical, suggesting that when unemployment is high, mortality declines as the time costs of health-producing activities also goes down (Ruhm 2000). This original finding has been extended and challenged in subsequent research with mixed findings, except in the case of mental health. Adult mental health outcomes worsen during economic downturns (Ruhm 2005, Charles and DeCicca 2008, Ruhm 2013, Stevens, Miller et al. 2013). A related and burgeoning literature examines the effects of the Great Recession on physical and mental health of adults and the elderly (Davalos and French 2011, McInerney and Mellor 2012, McInerney, Mellor et al. 2013), eating habits (Dave and Kelly 2012), suicide (Houle and Light 2014), hospitalizations and emergency department use (Currie and Tekin 2015), and demand for psychotropic medication (Bradford and Lastrapes 2013). In each case, the recession coincided with negative health impacts. 
Overall, the existing body of research has made important and influential contributions to the consequences of economic downturns and the understanding of health production, but this literature typically excludes children from analyses, leaving important questions unanswered. Two previous studies examine the impact of changes in economic conditions, measured by statelevel unemployment rates or county-level anticipated job losses, in-utero and find different results for birth weight (Dehejia and Lleras-Muney 2004, Carlson 2015), others find that individuals born during recessions live, on average, several years fewer than those born during economic expansions (Van Den Berg, Lindeboom et al. 2006). Beyond these studies that focus on in-utero and infant health exposures, the literature on effects of economic conditions on mental health is scant, with only two papers even mentioning child or adolescent health outcomes in relation to economic conditions and child health. Currie and Tekin use administrative hospital data from four states between 2005-2009 to estimate how within ZIP code increases in home foreclosures relate to hospitalizations, including admissions for psychiatric diagnoses (Currie and Tekin 2015). The paper studies all ages, but their main result holds for children. The most comparable research to our own examines how state-level job losses affect suicidality in adolescents (Gassman-Pines, Ananat et al. 2014). Using biennial data from the Youth Risk Behavior Surveillance Survey the research shows increases in the annual number of workers who lost jobs as a result of mass closings or layoffs are associated with more adolescent suicidality (suicidal thoughts or attempts). Taken together, the limited earlier research on economic conditions and mental health omitted young children, considered only suicidality in adolescents, relied on biennial data, and did not consider possible mechanisms linking economic conditions and mental health. 
The paucity of research on economic conditions and child and adolescent mental health is striking because mental health problems dominate the health issues facing this age group, Eleven percent of children 8-15 have mental disorders causing severe impairment (Merikangas, He et al. 2010); eight percent of adolescents annually experience a "severe emotional disturbance,” (Kessler, Avenevoli et al. 2012); and nearly half of mental health conditions in adulthood initiated in childhood or adolescence (Kessler, Berglund et al. 2005). Mental health problems in childhood and adolescence have major economic consequences, as well. Children with mental health conditions or emotional problems are more likely to use special education services, to repeat grades, to perform poorly on standardized tests and less likely to complete secondary education (Currie and Stabile 2006, Fletcher and Wolfe 2008). Untreated mental health problems can result in lower grades, initiation of substance use, and other risky behaviors (Busch, Golberstein et al. 2014). Poor health and economic outcomes in adulthood are correlated with childhood onset of mental health disorders (Currie 2009), and overall consequences of poor mental health in childhood exceed those of other childhood health problems (Case, Fertig, and Paxson 2005). One recent estimate suggests that child and adolescent mental disorders cost $\$ 247$ billion annually (National Research Council and Institute of Medicine 2009), based primarily on the internal, direct costs to individuals and families (e.g., costs of treatments and lost future productivity). However, the external costs are also large, as mental health problems in childhood and adolescence are linked to delinquent behavior (Busch, Golberstein et al. 2014), poorer academic outcomes for classmates (Aizer 2008), and higher levels of addiction and crime into adulthood (Fergusson, Horwood et al. 2007, Currie and Stabile 2009).

To summarize, little is known about the effect of economic conditions on children's mental health, despite the importance of child mental health for a myriad of health and social 
outcomes. Our research builds on evidence that economic conditions is an important contributor to mental health outcomes by examining consequences of economic conditions on children’s mental health and the use of services for children with emotional and behavioral problems.

\section{Potential Mechanisms}

Appropriate remedies to mitigate adverse effects of poor economic conditions on child mental health depend on which mechanisms link economic conditions to children’s mental health, with multiple possible channels. First, psychological and social stress within the household could be higher during recessions due to changes in parental employment and hours worked, a reduction or stagnation in earnings, the loss of social status, and financial pressure to pay bills and debt (DeNavas-Walt, Proctor et al. 2012, Hoynes, Miller et al. 2012, Weiland and Yoshikawa 2012, Kalil 2013). Even without any change in employment situation, poor economic conditions can increase stress for parents due to increased job insecurity among the employed and fewer opportunities for finding work among the unemployed (Carlson 2015). Meanwhile, people unaffected by job loss but living in neigborhoods with declining social cohesion or deteriorating physical structures due to recessions may feel additional strain. Increased family stress during economic recessions may result in increasing intrafamily conflict (Conger and Donnellan 2007) and, at the extremes, child maltreatment (Stephens-Davidowitz 2013).

In addition to stress-related pathways, other financially-related mechanisms -- including reductions in income and changes in time cost -- link economic conditions to children's mental health. For example, children's mental health suffers in the face of declining family income (Milligan and Stabile 2011) or parental job loss (Johnson, Kalil et al. 2010). In a similar manner, job loss or income declines could reduce health insurance coverage and use of mental health 
services (Schaller and Stevens 2014, Cawley, Moriya et al. 2015). Finally, while economic recessions may reduce time-costs for parents, spending more time with children may affect children negatively if parents are stressed during spells of unemployment, as biomarkers of child stress are correlated with parental mental health (Lupien, King et al. 2000). We do not describe all possible mechanisms linking economic conditions and children's mental health, but merely note the extensive evidence on a variety of mechanisms suggesting that economic conditions may negatively affect children's mental health.

\section{Methods}

\subsection{National Health Interview Survey}

To explore the relationship between economic conditions and children's mental health, we use annual cross-sectional data from the 2001-2013 National Health Interview Survey (NHIS). Conducted by the National Center of Health Statistics (NCHS), the NHIS is a nationally representative survey of the civilian non-institutionalized population in the United States (National Center for Health Statistics, 2013). The family core questionnaire records basic demographic, health, and disability information for each household member. A single randomly selected adult and child in each household receive detailed interview questions about health information. All responses are self-reported in a face-to-face interview with an NCHS surveyor.

\subsection{Measures of Childhood Mental Health}

Since 2001, the NHIS has collected data on the mental health of children and adolescents ages 4-17 using measures developed in the Child Strength and Difficulties Questionnaire (SDQ) (Bourdon, Goodman et al. 2005). Children do not respond directly to the NHIS, but a 
knowledgeable adult—nearly always a parent or guardian—answers questions regarding the health of the randomly-selected child per household (the "sample child").

The SDQ assesses psychopathology and social adjustment in young children and adolescents. The original questionnaire includes 25 core items across 5 domains (emotional symptoms, conduct problems, hyperactivity-inattention, peer problems, and prosocial behavior) and can be administered to parents, teachers and children (Goodman 2001). SDQ scores are highly predictive of mental illness. For instance, the prevalence of DSM-IV diagnoses of mental illness (as determined by an independent clinical rater) was 46 percent in the top decile of SDQ scores, compared to 5 percent in the lower 90 percent of SDQ scores (Goodman 2001). SDQ scores are highly correlated with outcomes such as the use of mental health services, special education services, or early intervention services (Pastor, Reuben et al. 2012). Parent-reported SDQ scores also correlate highly with teacher and child assessments (Goodman 2001).

One potential limitation of any parent-reported measure of child mental health, including the SDQ, is that we cannot distinguish whether economic conditions have true effects on child mental health status, or whether we simply capture changes in parental perceptions and reporting of child mental health as a response to economic conditions. We think parent-reported measures are meaningful in this context for several reasons. First, parent-reported SDQ scores correlate well with teacher and child assessments, and with independent clinical assessments (Goodman 2001). Second, we test, and confirm that, as parent reports of child mental health deteriorate, use of special education and early intervention services rise as well, which we interpret as having an objective and meaningful economic impact on the child and schools with limited resources. To obtain special education services, school officials must independently assess a child's need for 
services, implying that the parent's depressed mood, for example, is not simply coloring the view of child mental health.

In 2001-2013, the NHIS collected only five of the 25 SDQ items, which were chosen based on their high correlations with the original five SDQ domains. The interviewer introduced the SDQ items by stating, "I am going to read a list of items that describe children. For each item, please tell me if it has been not true, somewhat true, [or] certainly true for [Sample Child] during the past 6 months.”

- He/She gets along better with adults than with other children/youth.

- He/She has good attention span, sees chores or homework through to the end.

- He/She is often unhappy, depressed or tearful.

- He/She is generally well behaved, usually does what adults request.

- He/She has many worries, or often seems worried.

Each response is scored 0,1 or 2, with higher numbers corresponding to worse outcomes. The five items are then summed to form a summary child mental health score ranging from 0 (least likely to have psychological problems) to 10 (most likely to have psychological problems). We use the raw SDQ score as a continuous measure of mental health severity, and a binary measure that distinguishes children with psychological problems based on the NCHS’s recommended threshold score of six or higher to predict serious psychological problems (Pastor, Reuben et al. 2012). Unfortunately, these five questions from the SDQ were excluded from the NHIS in 2008 and 2009 due to budget shortages, although they are present in subsequent years.

The NHIS maintained a single, global measure of emotional disturbance throughout 2001-2013. This measure is the first question from the SDQ “Impact Scale,” a supplemental set 
of questions developed to better measure children's degree of impairment. Psychometric research finds that this full supplemental scale also predicts independent diagnosis of DSM-IV mental illness (Goodman 1999). A knowledgeable respondent answered the following question for each randomly selected sample child:

- Overall, do you think that [Sample Child name] has difficulties in any of the following areas: emotions, concentration, behavior, or being able to get along with other people?

Respondents could indicate no (0), yes with minor (1), yes with definite (2), or yes with severe (3) difficulties. We use two outcomes based on this measure of Emotional Difficulties: a continuous measure of mental health severity, and a binary measure that codes someone with definite or severe difficulties as having a likely psychological problem. Psychometric research documents that this single item predicts psychiatric disorder nearly as well as the full Impact Supplement, with a kappa measure of 0.72 indicating high agreement between this measure and psychiatric disorder (Goodman 1999, Pastor, Reuben et al. 2012).

We further demonstrate the value of the NHIS mental health measures with data on mental health treatment and medication use available in the 2005-2007 NHIS. We show the share of children reported ever taking medication for emotional problems, ever seeing or talking to a provider for emotional problems, and ever receiving treatment for emotional problems, broken out by whether there is a likely psychological problem based on the 5-question SDQ (Figure 1), and based on the Emotional Difficulty item (Figure 2). Both the measures strongly predict mental health-related treatments. For instance, 45 percent of children with likely psychological problems (based on the SDQ) received treatment for emotional problems at some 
point in their lives, compared to six percent of those without a likely psychological problem outcome. Fifty-five percent of children with likely psychological problems (based on the Emotional Difficulties item) ever received treatment, compared to five percent of those without likely psychological problems. Combined with the psychometric evidence cited above, this demonstrates that the NHIS's mental health items are meaningful measures of child mental health status.

\subsection{Empirical models}

We estimate the following model to empirically assess the effect of economic conditions on children's mental health status:

$$
(1) \text { KidsMH }_{i j t}=\alpha_{i j t}+\beta \text { Economic Conditions }_{j t}+\gamma X_{i j t}+\delta \text { State }_{j}+\lambda \text { Quarter }_{t}+\varepsilon_{i j t} \text {. }
$$

$K i d s M H_{i j t}$ represents a measure of child mental health status for a child $i$, observed in state $j$ in quarter $t$. Economic Conditions measures state-level economic conditions (unemployment rate or housing price index), in quarter t. $X$ is a vector of child covariates including age, sex, and racial/ethnic group, and family-level covariates including highest level of parental education, average age of parents, and whether parents are single or married. State is a set of state fixed effects, and Quarter is a full set of 58 quarter fixed effects (44 fixed effects in the models of the 5-item SDQ scale that exclude 2008-9). The specification in equation 1 yields estimates of the effect of changes in economic conditions within states, over time on child mental health. We also estimate versions of our models that include state-specific linear time trends.

We focus on the state as the "area” for defining economic conditions. A priori, it is unclear whether the state or a more local definition of the relevant area for measuring economic conditions is preferable (Lindo 2015). State-level measures may be subject to less measurement 
error and to less bias due to endogenous migration in response to poor economic conditions than local measures, although more-local measures may be closer approximations to the economic conditions faced by any given household. In separate analyses we define economic conditions at the Metropolitan Statistical Area (MSA) level, and find similar results. For brevity, we do not present MSA level models, but these results are available upon request.

We examine two measures of state-level economic conditions. The first is the unemployment rate, the most commonly used measure in studies linking economic conditions to health outcomes. Our quarterly measures of unemployment rates are defined as the percent of the population aged 16 years and older who are in the labor force but not currently employed. These come from publicly-available Bureau of Labor Statistics data. Our second measure of area-level quarterly economic conditions is the Freddie Mac Housing Price Index (HPI). The HPI measures state-level housing price appreciation and depreciation by tracking repeat transaction prices of one-family detached and townhome properties. The HPI has recently been used to link local changes in housing prices to antidepressant prescription volume among the near elderly between 55 and 64 years of age (Lin, Ketcham et al. 2013). The HPI is measured relative to a normalized base-year value of one (i.e., an HPI of 1.5 would represent housing prices $50 \%$ higher than the base year). We were able to link state-level economic indicators to the NHIS microdata via a restricted data agreement with the NCHS.

We estimate OLS models of the continuous outcomes for ease of interpretation and to reduce computational burden. However, negative binomial models of the SDQ summary score and ordered probit models of the Emotional Difficulties question yield quantitatively similar findings. For the models of binary outcomes we estimate probit regressions and present marginal effects in the tables. In all models, we use NHIS sample weights to make estimates reflect the 
target national population. Standard errors are clustered at the state level (Bertrand, Duflo et al. 2004).

The summary statistics are described in Table 1. The average child's age is 10.5 years, approximately 60 percent of children are white, 14 percent are black, 20 percent are Hispanic, 6 percent are “other” races or ethnicities, and approximately 28 percent live in single parent households. The average mental health severity based on the SDQ score is 1.7, and four percent of children have a likely psychological problem based on their SDQ scores. The average mental health severity based on the Emotional Difficulties item, is 0.26 , and 5.0 percent of children have a likely psychological problem based on their Emotional Difficulty score. Few children, 2.4 percent, use special education services for emotional or behavioral problems.

\section{Results}

\subsection{The overall effects of economic conditions on children's mental health status}

Table 2 presents the results for the SDQ-derived outcomes. Child mental health deteriorates in a weakening economy. Increases in state unemployment rates lead to significantly worse mental health severity (marginal effect $=0.026$ for each percentage point increase in the state unemployment rate), as measured by higher SDQ scores (Panel A, Column 1). Results for MSA-level measures are similar in size and precision but slightly smaller, in general (available upon request). The estimated impact of economic conditions is larger in magnitude when statespecific linear time trends are included (Panel A, Column 2). We also find that increases in the state-level HPI lead to significantly better (i.e. lower) SDQ scores (Panel B, Column 1), and the results are similar when state-specific time trends are included. The magnitudes of the effects are similar across the two measures of economic conditions when considering relative effects. A 
one-standard deviation improvement in state-level unemployment rates (1.51 percentage points) and HPI (0.19) leads to a 2.3 percent and 2.0 percent improvement in SDQ scores, respectively. Columns 3 and 4 of Table 2 show the results for probit models of the likelihood of a psychological problem, based on the SDQ score. ${ }^{1} \mathrm{~A}$ one-standard deviation improvement in unemployment rates leads to an 11 percent reduction in the likelihood of a psychological problem. The effect of a one-standard deviation improvement in state-level HPI leads to a 6.4 percent drop in the likelihood of a psychological problem. The results are similar in strength and precision when state-specific time trends are included in the models (Column 4).

A similar overall pattern of results is found when we examine outcomes based on the Emotional Difficulties item in Table 3, although the relative magnitudes of the effects are slightly larger than in the SDQ-based outcome models. Increases in state unemployment lead to worse mental health severity (Table 3, Panel A, Column 1). Increases in the state HPI, (i.e., improving economic conditions), lead to significantly improved mental health severity (Table 3, Panel B, Column 1). For both unemployment rates and HPI, the point estimates are very similar regardless of whether state-specific time trends are included, although the point estimate on state unemployment rates is just outside the bounds of significance when the state-specific time trends are included. The relative effects are similar across the two measures of economic conditions. A one-standard deviation improvement in state-level unemployment rates and HPI leads to a 4.8 percent and 4.7 percent relative improvement in mental health severity, respectively, in the models without area-time trends. The results are broadly similar for the likelihood of clinicallymeaningful psychological problems (Table 3, Columns 3-4). A one-standard deviation

\footnotetext{
${ }^{1}$ Results from linear probability models are similar, but we prefer probit models because of the low probabilities of the outcomes.
} 
improvement in state-level econonic conditions leads to a $7.4 \%$ to $10.4 \%$ reduction in the likelihood of psychological problems. Finally, we find that the effects of economic conditions on the likelihood of having psychological problems is even greater than for the continuous measures of mental health severity, suggesting that economic conditions matter more for children at risk of serious mental or emotional problems.

For all of the results reported thus far, the point estimates are nearly identical if we exclude the family-level covariates (parental education, average age of parents, and whether parents are single or married) from the model (available upon request). However, our results are slightly more precise if they are included. The stability of the point estimates with respect to family characteristics suggests that the estimates reflect actual effects of economic conditions, rather than compositional changes driven by selective migration along the dimensions of socioeconomic status, household structure, and parental age.

We also explore whether unemployment rates and HPI exert independent effects on child mental health when included in a model simultaneously. A priori we expect that we are less likely to find independent effects because the measures are highly correlated with each other. ${ }^{2}$ The results of these models are presented in Appendix Tables 1 and 2, and indeed show independent effects that are smaller and less-precise than the results in Tables 2 and 3, although we do find a few statistically significant and independent effects, mostly for the independent effects of HPI.

\subsection{Do the Effects of Economic Conditions Vary by Sex or Age?}

\footnotetext{
${ }^{2}$ The correlation between the residuals of state unemployment rates and HPI, after accounting for state and quarter fixed effects, is -0.50 .
} 
In this section, we assess whether the effects of economic conditions on child mental health are heterogeneous along two important dimensions, sex and age. Table 4 presents results based on the SDQ and Table 5 presents results based on the Emotional Difficulties Item. Looking within each sex group and within each age group (4 to 11 versus 12 to 17), worsening economic conditions have a negative impact on mental health. The relative size of the impact varies from a 1.1 percent increase in mental health severity among children 4 to 11 as HPI falls, to an 18.9 percent increase in the chance of having a psychological problem for females. Still, across each specification, rising unemployment or falling housing prices coincide with worse mental health. Throughout Tables 4 and 5, we reported the results of models without controlling for state-specific linear time trends. The estimated results are similar with state-specific linear time trends (available upon request).

\subsection{True effects, or effects on parental reporting?}

The estimates that we have reported thus far could represent true effects of economic conditions on mental health, or they could also represent changes in parental reporting about children's mental health status. We take two approaches to address this important issue. First, we examine how patterns of mental health status within the household respond to economic conditions. In this analysis, we look jointly at parent and child mental health. Adult mental health is measured by Kessler's K6 instrument for serious psychological distress in the NHIS, which is collected from the randomly-selected "sample adult" in each household (which could be a child's parent or other adults in the household). We use the recommended threshold of a K6 score of 13 or higher to define poor parental mental health (Kessler, Barker et al. 2003). 
The goal of this analysis is to assess whether parental and child mental health move together, so that a bad economy hurts mental health status for both parents and children jointly, or whether adverse mental health effects move independently for parents and children. If we found that the effects on parental and child mental health move together, it is more likely that child mental health estimates reflect changes in parental reporting rather than true changes in children's mental health. To determine whether parental mental health responds simulteanously with children's mental health under similar economic conditions, we estimate a bivariate probit model of poor parental mental health jointly with the child's likelihood of psychological problems based on the SDQ scale, using the same specification as equation 1 for both equations in the bivariate probit model.

In Table 6 we report the marginal effects of state-level unemployment rates and housing prices on the joint densities of child and parent mental health (both poor, neither poor, child poor, parent poor). Increases in unemployment rates decrease the likelihood that both parent and child report good mental health. This decline in mental health is offset by increases in the likelihood of only the child (not parent) reporting poor mental health, only the parent (not child) reporting poor mental health, and neither parent nor child reporting poor mental health; listed by decreasing size of marginal effect. For the HPI measure, the pattern is similar - when housing prices drop the likelihood of both parent and child having good health decreases, but this is mostly offset by increases in the likelihood of only the parent or only the child reporting poor mental health. In other words, when economic conditions worsen, household levels of mental health problems rise, but this is driven more by increases in either the parent or the child reporting poor mental health than it is by both parent and child reporting poor mental health. This suggests that the main results are not being driven by changes in parental reporting. 
In our second approach to addressing the possible association between parental and children's mental health, we examine whether the main results are sensitive to including parental mental health as a covariate. This approach is limited in that it includes an endogenous variable, parental mental health, as a covariate. However, if the main results were sensitive to including parental mental health, it would suggest that lower child mental health during bad economic times could reflect changes in parental reporting as the economy changed rather than true changes in children's mental health. We find that the results are not sensitive to including parental mental health; the point estimates and significance are nearly the same as the main results (available upon request), suggesting, again, that the main results are not driven by changes in parental reporting.

\subsection{Effects on Services for Emotional or Behavioral Problems}

Thus far, we have shown evidence of the negative effect of poor economic conditions on children's mental health status, and we found that economic conditions affect both boys and girls and affect both younger children and adolescents. Next we turn to the effect of economic conditions on an important consequence of poor mental health: the use of special education services for children's emotional problems. Only one emotional/behavioral services measure in the NHIS is available throughout our study period: whether a child used special education or early intervention services in the past 12 months specifically for an emotional or behavioral problem. This question was asked of all children under 18 from 2001 on, yielding a substantially larger sample size than the main children's mental health questions, although we focus on ages 4-17 for consistency with our analyses of mental health status. Among 4-17 year olds, respondents reported that 2.4 percent had used special education or early intervention services for emotional or behavioral problems in the past 12 months. 
This measure has strengths and limitations. First, special education or early intervention services represent an extreme measure of service use for emotional problems, as many children using mental health services do not use or qualify for such special education services. Second, the supply of special education and early intervention services could be counter-cyclical, as these services are largely financed by state and local governments, where budgets are more constrained in a poor economy. Thus, one might miss a change in true underlying demand for these services if constrained budgets limited children's access to such services. In defense of this measure of service use, special education and early intervention services represent the use of very intensive services for children with mental health problems. This outcome also reflects mental health problems that are long-lasting, as the NHIS questionnaire explicitly defines emotional or behavioral problems in this context to be chronic, and not short-term, difficulties. This measure is also unlikely to be subject to concerns about biased parental reporting, since children must be evaluated by many different adults, not just parents, to qualify for special education services. And, as these services are expensive and largely publicly-financed, any increases in the use of these services indicate that poor economic conditions have direct consequences for state and local budgets. The cost of educating a special education student is estimated to be 90 percent higher than educating a student without special needs, and the relative expense of these services is even higher in small school districts (Chambers, Parrish et al. 2004).

We report the results of probit models of special education and early intervention services for emotional problems in Table 7. In models without state-specific linear time trends, we find that rising unemployment rates, and falling housing prices, increase the use of special education services for emotional problems. A one-standard deviation improvement in the state-level unemployment rate decreases the use of special education services by 5.7 percent relative to the 
mean, and a one-standard deviation increase in housing prices decreases special education use by 3.2 percent relative to the mean. The magnitudes of these results are sensitive to whether one controls for state-specific linear time trends (which yields a bigger, less precise estimated effect for unemployment rates; and a smaller, insignificant effect for housing prices). That we also find effects of economic condition on this outcome that is relatively "objective” compared to children's mental health status further reinforces our interpretation that the effects on children's mental health status are not an artifact of changes in parental reporting of symptoms.

\subsection{Investigating Parental Employment as a Mechanism}

Understanding the mechanisms behind the overall effects of economic conditions on children's mental health is valuable for the literature on economic conditions and health in general, and understanding mechanisms is crucial for informing optimal policy responses to economic downturns. In this section we investigate potential mechanisms, with a focus on parental employment. We focus on parental employment because job loss and unemployment are among the main, if not the main, ways that economic conditions affect families and households. Other potential mechanisms (e.g., income, stress, parental time use) are also strongly mediated by family-level employment (Kalil 2013). The challenge in identifying the mediating role of parental employment is that it is complicated to interpret the results of models stratified by the actual employment status within the household, due to the endogeneity of employment. Therefore, we take three complementary approaches to understand the role that parental employment plays in explaining our results.

In the first approach, we examine subgroups with different risks of unemployment during economic recessions. One study on adult mental health in men (Charles and DeCicca 2008) 
stratifies mental health effects by educational attainment and race/ethnicity, motivated by the argument that lower socioeconomic groups were more likely to experience job losses during recessions. Thus, if unemployment effects are stronger within groups most likely to experience job loss during a poor economy, it might provide some evidence that the effects we observe are mediated by household-level employment outcomes. ${ }^{3}$ In this set of analyses, we stratify children by the highest level of parental educational attainment in the household, defined as less than a bachelor's degree versus at least a bachelor's degree. We also estimate models stratified by the child's race and ethnicity (defined as non-Hispanic white or other). Recent research documents that lower educational attainment and racial/ethnic minority groups experience greater declines in employment during economic downturns (Hoynes, Miller et al. 2012).

Tables 8 and 9 show the results of these stratified models predicting the likelihood of psychological problems based on the SDQ and on the emotional difficulty item, respectively. The effects of unemployment rates and housing prices are stronger and only statistically significant for lower-education families, across both outcomes. In contrast, the effects of economic conditions on children’s mental health are mostly similar across racial/ethnic groups that had different employment responses to economic conditions. Taken together, these findings suggest that parental employment may be an important mediator of the effect of economic conditions on child mental health, but not the sole mediator. However, these results need to be interepreted with the caveat that there are a variety of differences across these groups that could also explain heterogeneous effects of economic conditions on children's mental health. ${ }^{4}$

\footnotetext{
${ }^{3}$ Any heterogeneous results may also reflect a host of other factors associated with low socioeconomic status, as well.

${ }^{4}$ We also investigated differences by whether the household was one- or two-parent. The effects of economic conditions are also stronger for single-parent households (based emotional difficulty models), which may suggest that single parent families have fewer resources to buffer against negative economic shocks.
} 
Our second approach to understanding the possible mediating role of parental employment is to restrict the sample to children in two-parent families stratified by number of employed parents ( 0 or 1 , or 2$)$. This approach, shown in tables 8 and 9 , has the clear limitation that employment is endogenous and that differences across employment status will reflect a host of other factors that may be relevant to children's mental health. With that caveat in mind, we do not see any effects of economic conditions on children in two-parent families where both parents are employed, and we find some larger, though imprecisely estimated, effects for children in families with at least one unemployed parent (Tables 8-9, Columns 5-6). These results suggest that parental employment is likely to be an important mediator of the effect of economic conditions on children's mental health, but that conclusion should be interpreted with caution given the imprecision of our point estimates.

In our third approach to understanding whether the main mechanism behind our results is family-level employment, we estimate each household's “predicted employment," similar to Charles and DeCicca (2008) to gain a better sense of whether children living with parents more likely affected by the recession have larger mental health effects. Using the 2001 data, we estimated employment models for all adults as a flexible function of age, race, sex, and education. ${ }^{5}$ We then use the parameters from that model to predict employment status for all parents in the households. We then divide the sample of children into quintiles of the probability of having employed parents in their household (two-parent households were assigned the higher employment probability of the two parents). We then re-estimate our analyses after stratifying by low-predicted parental employment (bottom quintile), medium-predicted parental employment

\footnotetext{
${ }^{5}$ We included a quadratic in age, and interacted race/ethnicity with educational attainment. We estimated separate models by sex.
} 
(quintiles 2-4), and high-predicted parental employment (top quintile). We also estimate two economic outcomes directly. The estimated impacts of economic conditions on whether a child has any parent in the labor force but unemployed, and annual household income are shown in Panels A and B, to show how changes in state unemployment rates affect the families in the three predicted-employment groups.

The effect of unemployment rates on the likelihood of having an unemployed parent varies significantly across the predicted-employment groups. In households where parents are most likely to be employed (based on 2001 paramater estimates and current demographics), the probability of unemployment is not affected by state unemployment rates (Table 10, Panel A). As expected, the likelihood of parental unemployment rises with unemployment rates for the middle-predicted employment group, but the effect is considerably larger for the low-predicted employment group. On the other hand, unemployment rates have greater absolute effects on income for higher-predicted employment families, but the relative effects compared to mean family incomes are comparable across the three predicted-employment groups (Table 10, Panel B).

The results for the likelihood of severe psychological problems based on the SDQ and on the emotional difficulties item are shown in Panels C and D of Table 10, respectively. If our main effects were driven by family-level unemployment, we would expect to see the strongest effects on children's mental health in the lowest predicted-employment quintile, and little-to-no effects in the highest predicted-employment quintile. We do not see that pattern of results in Panels C and D. For the likelihood of severe psychological problems, there is no effect of unemployment rates for the lowest- predicted-employment quintile, and the effects for the middle- and high-predicted employment groups are similar to each other (and both are 
statistically significant). The pattern of results for the binary emotional difficulties outcome is different, with strongest effects in the bottom quintile of predicted employment. ${ }^{6}$ The effects for the middle- and high-predicted employment groups are the same, and both are statistically significant at $\mathrm{p}<0.10 .^{7}$

These results are inconsistent with what we would expect if the main results of economic condition on children's mental health were mediated entirely by family-level job losses, which suggests that other mechanisms are also important for explaining the effects of economic conditions on children's mental health. However, this approach to considering family-level employment as a mediator has important limitations. A priori, it is unclear whether the effect of economic conditions on children's mental health should vary monotonically over parents' predicted employment. Predicted employment status likely proxies for overall socioeconomic status, and it is possible that households across the socioeconomic continuum respond to economic stressors differently.

Besides parental employment, what else drives the relationship between child mental health and economic conditions? While we do not directly investigate other mechanisms in our data, we hypothesize on what might be the most-likely candidates. Income could be an important explanation even in absence of job loss or unemployment, since poor economic conditions could exert downward pressure on wages or lead to shifts toward more part-time employment. Additionally, strong evidence documents causal effects of income on children's mental health (Milligan and Stabile 2011). Another possibility is that the stress of experiencing bad economic

\footnotetext{
${ }^{6}$ The different patterns across predicted employment groups between the SDQ and Emotional Difficulties outcomes are not explained by the missing SDQ measures in 2008-2009. The Emotional Difficulties results are nearly identical when we exclude 2008-2009.

${ }^{7}$ The results in Table 8 are quite similar if we use deciles of predicted unemployment-but-in-labor force to divide the three groups (Appendix Table 3).
} 
conditions could affect children's mental health, independently of parental employment status and income. For examples, recent research shows that the release of distressing economic news and job insecurity significantly reduces birth weight, and that rising foreclosures are linked to suicides (Houle and Light 2014, Carlson 2015). One potential mechanism that we do not think is likely to be an important mediator is the spillover of parental to child mental health, as we previously noted that including parental mental health as a covariate does not alter our results.

\section{Discussion}

We provide novel evidence on the effect of economic conditions on direct measures of child and adolescent mental health and use of special education services. We find that measures of mental health in children deteriorates when the economy is bad. The estimated effects of economic conditions on child mental health are comparable regardless of whether we measure economic activity with unemployment rates or a housing price index. The magnitudes of the effects are comparable to other estimates of effects of economic conditions on a variety of adult health outcomes. For example, prior research finds that a one percentage point rise in state unemployment rates increased adult suicide mortality by 1.3 percent (Ruhm 2000) and increased the likelihood of reporting fair or poor health among older adults by 2.0 to 11.2 percent (McInerney and Mellor 2012). We find that a similar rise in unemployment rates increased levels of mental health problem severity by 1.5 to 2.5 percent, and the probability of clinically meaningful mental health problems rises by 6.9 to 10.4 percent. In other words, our results imply that during the Great Recession when unemployment rates rose 5 percentage points, the probability of clinically meaningful child mental health problems increased by 35 to 50 percent. Consistent with the rise in mental health problems during recessions, the likelihood of using special education and early intervention services increases by 3.8 to 4.2 percent for each 
percentage point rise in unemployment rates, underscoring that changes in child mental health during recessions are important not just within a child's family, but also for the school districts serving them.

As another way to frame our results, a recent paper considers the effects of a $\$ 1,000$ tax credit on child mental health, using a different but comparable measure of mental health (Milligan and Stabile 2011). They find that an additional \$1,000 leads to relative improvement in children's mental health status similar to those we estimate for a one percentage point decrease in unemployment rates. Considering that the Great Recession brought a 5 percentage point rise in the unemployment rate in the U.S. (with much larger rises in some states and MSAs), our results imply that mental health of children declined by an amount comparable to a loss of income of $\$ 5,000$, a figure consistent with actual changes in family income that occur as unemployment rates rise.

Which mechanisms explain the effects that we see? A prominent candidate is the effect of unemployment and job loss within the household. However, we do not consistently find that children with parents at highest risk of unemployment worse off. Children from some types of families likely to become unemployed in a bad economy (e.g., children living with parents that did not complete college) have larger reductions in mental health than other children, but other types of families most likely to become unemployed in a bad economy (e.g., non-white families) do not. We infer from this mixed set of results that household-level unemployment does not appear to be the main driver of our results. Income losses and fears of job losses that accompany a weak economy, even among the employed, offer other plausible mechanisms to explain the child mental health effects. 
One important consideration is whether the effects that we report in this paper reflect true effects on child mental health status, or whether economic conditions just affect parental perceptions and reporting of child mental health. We have three arguments in favor of "true" effects. First, parent-reported SDQ scores correlate well with teacher and child assessments, and with independent clinical assessments (Goodman 2001). Second, child mental health outcomes move independently of parent mental health, and the effect of economic conditions on child mental health remained unchanged in models controlling for parental mental health status. Third, we find evidence that economic conditions affect the use of special education and early intervention services for emotional problems -- a more objective measure of child mental health. We cannot definitively rule out changing parental perceptions as one explanation for our findings, but our results suggests that this would be unlikely to explain more than a small share of the effects we observe.

We estimate short-term child health responses to shocks in local economic conditions. Our approach does not permit us to answer the questions regarding economy-wide and longerlasting economic downturns, or whether the effects on mental health are transitory or persistent. However, even short-term mental health problems can have serious consequences in childhood and adolescence (Currie and Stabile 2009, Busch, Golberstein et al. 2014). Furthermore, when asking respondents about special education, the NHIS explicitly refers to services for chronic, and not short-term, difficulties, offering further support for the notion that child mental health effects persist over time. The effects on special education use also represent a large effect of economic conditions on special education systems and their financing. Among the 57.1 million non-institutionalized children ages 4-17 represented annually in the 2001-2013 NHIS, approximately 1.4 million children annually received special education specifically for emotional 
or behavioral problems. Our estimates suggest that a standard deviation increase in unemployment rates would increase the number of children in special education by at least 80,000 nationally. Under the assumption that the difference in annual spending between a special education student and a regular education student is approximately \$8,250 in 2016 dollars (Chambers, Parrish et al. 2004), this implies an annual increase in spending of approximately $\$ 660$ million that is largely financed by state and local governments.

Along with providing new insight into the production of child mental health, our results have implications for policy responses to poor economic conditions. We confirm that the consequences of a bad economy extend beyond labor market participants. These spillover effects to child mental health suggest that common responses to weak economic conditions may have larger effects than anticipated. Interventions like extending unemployment benefits to cushion the loss of income, for example, may have benefits for child health that get overlooked. Countercyclical investments in children's mental health resources may also yield benefits, given the short- and long-term negative consequences of poor mental health in childhood. A better understanding of the mechanisms linking economic conditions to child mental health would help guide the optimal design of policy response during recessions. 


\section{References}

Aizer, A. (2008). "Peer Effects, Institutions, and Human Capital Accumulation: The Externalities of ADD." NBER Working Paper w14354.

Bertrand, M., E. Duflo and S. Mullainathan (2004). "How much should we trust differences-indifferences estimates?" Quarterly Journal of Economics 119(1): 249-275.

Bourdon, K. H., R. Goodman, D. S. Rae, G. Simpson and D. S. Koretz (2005). "The Strengths and Difficulties Questionnaire: U.S. normative data and psychometric properties." J Am Acad Child Adolesc Psychiatry 44(6): 557-564.

Bradford, W. D. and W. D. Lastrapes (2014). "A Prescription for Unemployment? Recessions and the Demand for Mental Health Drugs." Health Economics 23(11): 1301-1325.

Busch, S., E. Golberstein and E. Meara (2014). "FDA and ABCs: The Unintended Consequences of Antidepressant Warnings on Adolescent Human Capital Outcomes." Journal of Human Resources 49(3): 540-571.

Carlson, K. (2015). "Fear itself: The effects of distressing economic news on birth outcomes." $\underline{\mathrm{J}}$ Health Econ 41: 117-132.

Case, A., A. Fertig and C. Paxson (2005). "The lasting impact of childhood health and circumstance." Journal of Health Economics 24(2): 365-389.

Cawley, J., A. S. Moriya and K. Simon (2015). "The impact of the macroeconomy on health insurance coverage: evidence from the Great Recession." Health Econ 24(2): 206-223.

Chambers, J. G., T. B. Parrish and J. J. Harr (2004). What Are We Spending on Special Education Services in the United States, 1999-2000? , American Institutes for Research.

Charles, K. K. and P. DeCicca (2008). "Local labor market fluctuations and health: Is there a connection and for whom?" Journal of Health Economics 27(6): 1532-1550.

Conger, R. D. and M. B. Donnellan (2007). "An interactionist perspective on the socioeconomic context of human development." Annual Review of Psychology 58: 175-199.

Currie, J. (2009). "Healthy, Wealthy, and Wise: Socioeconomic Status, Poor Health in Childhood, and Human Capital Development." Journal of Economic Literature 47(1): 87-122.

Currie, J. and M. Stabile (2006). "Child mental health and human capital accumulation: The case of ADHD." Journal of Health Economics 25(6): 1094-1118.

Currie, J. and M. Stabile (2009). Mental Health in Childhood and Human Capital. An Economic Perspective on the Problems of Dsiadvantaged Youth. J. Gruber. Chicago, University of Chicago Press for NBER. 
Currie, J., M. Stabile, P. Manivong and L. L. Roos (2010). "Child Health and Young Adult Outcomes." Journal of Human Resources 45(3): 517-548.

Currie, J. and E. Tekin (2015). "Is There a Link between Foreclosure and Health?" American Economic Journal-Economic Policy 7(1): 63-94.

Davalos, M. E. and M. T. French (2011). "This Recession Is Wearing Me Out! Health-Related Quality of Life and Economic Downturns." Journal of Mental Health Policy and Economics 14(2): 61-72.

Dave, D. M. and I. R. Kelly (2012). "How does the business cycle affect eating habits?" Social Science \& Medicine 74(2): 254-262.

Dehejia, R. and A. Lleras-Muney (2004). "Booms, busts, and babies' health." Quarterly Journal of Economics 119(3): 1091-1130.

DeNavas-Walt, C., B. Proctor and J. Smith (2012). Income, Poverty, and Health Insurane Coverage in the United States: 2011. Current Population Reports. U. S. C. Bureau. Washington, DC, U.S. Government Printing Office.

Fergusson, D. M., L. J. Horwood and E. M. Ridder (2007). "Conduct and attentional problems in childhood and adolescence and later substance use, abuse and dependence: results of a 25-year longitudinal study." Drug Alcohol Depend 88 Suppl 1: S14-26.

Fletcher, J. and B. Wolfe (2008). "Child mental health and human capital accumulation: The case of ADHD revisited." Journal of Health Economics 27(3): 794-800.

Gassman-Pines, A., E. O. Ananat and C. M. Gibson-Davis (2014). "Effects of statewide job losses on adolescent suicide-related behaviors." Am J Public Health 104(10): 1964-1970.

Goodman, A., R. Joyce and J. P. Smith (2011). "The long shadow cast by childhood physical and mental problems on adult life." Proceedings of the National Academy of Sciences of the United States of America 108(15): 6032-6037.

Goodman, R. (1999). "The extended version of the Strengths and Difficulties Questionnaire as a guide to child psychiatric caseness and consequent burden." J Child Psychol Psychiatry 40(5): 791-799.

Goodman, R. (2001). "Psychometric properties of the strengths and difficulties questionnaire." Am Acad Child Adolesc Psychiatry 40(11): 1337-1345.

Houle, J. N. and M. T. Light (2014). "The home foreclosure crisis and rising suicide rates, 2005 to 2010." Am J Public Health 104(6): 1073-1079.

Hoynes, H., D. L. Miller and J. Schaller (2012). "Who Suffers During Recessions?" Journal of Economic Perspectives 26(3): 27-47. 
Johnson, R. C., A. Kalil and R. E. Dunifon (2010). Mothers' Work and Children's Lives: LowIncome Families After Welfare Reform. Kalamazoo, MI, W.E. Upjohn Institute for Employment Research.

Kalil, A. (2013). "Effects of the Great Recession on Child Development." Annals of the American Academy of Political and Social Science 650(1): 232-249.

Kessler, R. C., S. Avenevoli, J. Costello, J. G. Green, M. J. Gruber, K. A. McLaughlin, M. Petukhova, N. A. Sampson, A. M. Zaslavsky and K. R. Merikangas (2012). "Severity of 12month DSM-IV disorders in the National Comorbidity Survey Replication Adolescent Supplement." Arch Gen Psychiatry 69(4): 381-389.

Kessler, R. C., P. R. Barker, L. J. Colpe, J. F. Epstein, J. C. Gfroerer, E. Hiripi, M. J. Howes, S. L. Normand, R. W. Manderscheid, E. E. Walters and A. M. Zaslavsky (2003). "Screening for serious mental illness in the general population." Arch Gen Psychiatry 60(2): 184-189.

Kessler, R. C., P. Berglund, O. Demler, R. Jin, K. R. Merikangas and E. E. Walters (2005). "Lifetime prevalence and age-of-onset distributions of DSM-IV disorders in the National Comorbidity Survey Replication." Arch Gen Psychiatry 62(6): 593-602.

Lin, H. Z., J. D. Ketcham, J. N. Rosenquist and K. I. Simon (2013). "Financial distress and use of mental health care: Evidence from antidepressant prescription claims." Economics Letters 121(3): 449-453.

Lindo, J. M. (2015). "Aggregation and the estimated effects of economic conditions on health." $\underline{\mathrm{J}}$ Health Econ 40: 83-96.

Lupien, S. J., S. King, M. J. Meaney and B. S. McEwen (2000). "Child's stress hormone levels correlate with mother's socioeconomic status and depressive state." Biol Psychiatry 48(10): 976980.

McInerney, M. and J. M. Mellor (2012). "Recessions and seniors' health, health behaviors, and healthcare use: Analysis of the Medicare Current Beneficiary Survey." Journal of Health Economics 31(5): 744-751.

McInerney, M., J. M. Mellor and L. H. Nicholas (2013). "Recession depression: Mental health effects of the 2008 stock market crash." Journal of Health Economics 32(6): 1090-1104.

Merikangas, K. R., J. P. He, D. Brody, P. W. Fisher, K. Bourdon and D. S. Koretz (2010). "Prevalence and treatment of mental disorders among US children in the 2001-2004 NHANES." Pediatrics 125(1): 75-81.

Milligan, K. and M. Stabile (2011). "Do Child Tax Benefits Affect the Well-being of Children? Evidence from Canadian Child Benefit Expansions." American Economic Journal-Economic Policy 3(3): 175-205. 
National Research Council and Institute of Medicine (2009). Preventing Mental, Emotional, and Behavioral Disorders among Young People: Progress and Possibilities. Washington, D.C., The National Academies Press.

Pastor, P. N., C. A. Reuben and C. R. Duran (2012). "Identifying Emotional and Behavioral Problems in Children Aged 4-17 Years: United States, 2001-2007." National Health Statistics Reports Number 48.

Ruhm, C. J. (2000). "Are recessions good for your health?" Quarterly Journal of Economics 115(2): 617-650.

Ruhm, C. J. (2005). "Healthy living in hard times." Journal of Health Economics 24(2): 341-363.

Ruhm, C. J. (2013). "Recessions, Healthy No More?" Working Paper.

Schaller, J. and A. H. Stevens (2014). "Short-Run Effects of Job Loss on Health Conditions, Health Insurance, and Health Care Utilization." NBER Working Paper 19884.

Stephens-Davidowitz, S. (2013). "Unreported Victims of an Economic Downturn." Working Paper.

Stevens, A. H., D. L. Miller, M. E. Page and M. Filipski (2013). "The Best of Times, the Worst of Times: Understanding Pro-Cyclical Mortality." Working Paper.

Van Den Berg, G. J., M. Lindeboom and F. Portrait (2006). "Economic conditions early in life and individual mortality." American Economic Review 96(1): 290-302.

Weiland, C. and H. Yoshikawa (2012). "The Effects of Large-Scale Economic Change and Policies on Children's Developmental Contexts and Developmental Outcomes." Child Development Perspectives 6(4): 342-350. 

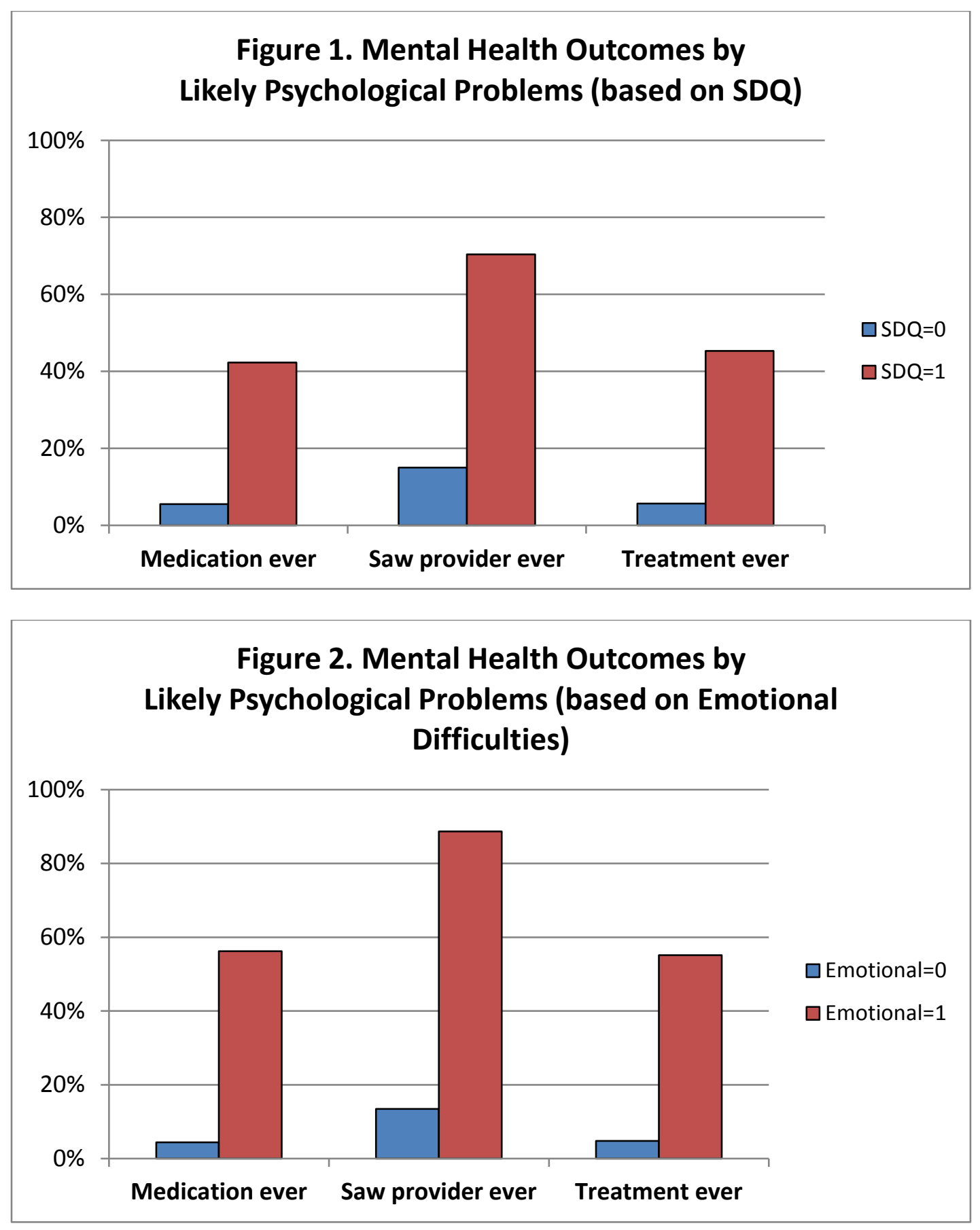

Source: 2001-2013 National Health Interview Survey.

Notes: SDQ=Strengths and Difficulty Questionnaire. Emotional=Emotional Difficulties Item 
Table 1. Summary Statistics of Children 4-17 years old, 2001-2013 National Health Interview Survey

\begin{tabular}{|c|c|}
\hline \multirow{3}{*}{$\begin{array}{l}\text { Age } \\
\text { (SD) }\end{array}$} & Sample Mean \\
\hline & 10.50 \\
\hline & (2.79) \\
\hline Male & 0.51 \\
\hline Non-Hispanic White & 0.60 \\
\hline Non-Hispanic Black & 0.14 \\
\hline Hispanic & 0.20 \\
\hline Other non-Hispanic races & 0.06 \\
\hline Parental education $<$ high school & 0.13 \\
\hline Single parent household & 0.28 \\
\hline $\begin{array}{l}\text { Quarterly State Unemployment Rate } \\
\text { (SD) }\end{array}$ & $\begin{array}{c}6.59 \\
(1.51)\end{array}$ \\
\hline $\begin{array}{l}\text { Quarterly State HPI } \\
\text { (SD) }\end{array}$ & $\begin{array}{c}1.31 \\
(0.19)\end{array}$ \\
\hline Outcomes Based on SDQ Score: & \\
\hline $\begin{array}{l}\text { Mental Health Severity } \\
\text { (SD) }\end{array}$ & $\begin{array}{l}1.713 \\
(1.21)\end{array}$ \\
\hline Likely Psychological Problem & 0.041 \\
\hline Outcomes Based on Emotional Difficulties Item: & \\
\hline $\begin{array}{l}\text { Mental Health Severity } \\
\text { (SD) }\end{array}$ & $\begin{array}{c}0.263 \\
(0.405)\end{array}$ \\
\hline Likely Psychological Problem & 0.051 \\
\hline $\begin{array}{l}\text { Any special education or early intervention services } \\
\text { due to mental or emotional problem }\end{array}$ & 0.0237 \\
\hline $\begin{array}{l}\text { Notes: Variable means with standard deviation (SD) } \\
\text { Strengths and Difficulties Scale, which ranges from } \\
\text { that higher scores reflect worse health. For both the } \\
\text { difficulties, higher scores indicate worse mental heal } \\
\text { are used. }\end{array}$ & $\begin{array}{l}\text { ntheses. SDQ is the } \\
\text { and was coded so } \\
\text { d Emotional } \\
\text { IS sampling weights }\end{array}$ \\
\hline
\end{tabular}


Table 2. Regression Results, Outcomes based on SDQ Scale

$\underline{\text { Panel A. State Unemployment Rate }}$

Mental Health Severity $\quad$ Likely Psychological Problem (0/1) $(0-10)$
(1)
(2)
(3)
(4)

\begin{tabular}{|c|c|c|c|c|}
\hline $\begin{array}{l}\text { Marginal Effect } \\
\text { (SE) }\end{array}$ & $\begin{array}{l}0.0263^{*} \\
(0.0132)\end{array}$ & $\begin{array}{l}0.0434 * * \\
(0.0163)\end{array}$ & $\begin{array}{l}0.0030 * * \\
(0.0012)\end{array}$ & $\begin{array}{l}0.0037 * * * \\
(0.0014)\end{array}$ \\
\hline Mean of DV & 1.71 & 1.71 & 0.041 & 0.041 \\
\hline \multirow{4}{*}{$\begin{array}{l}\text { Relative Effect of 1-SD } \\
\text { improvement in } \\
\text { economic conditions }\end{array}$} & $-2.3 \%$ & $-3.8 \%$ & $-11.0 \%$ & $-13.6 \%$ \\
\hline & \multicolumn{4}{|c|}{ Panel B. State Housing Price Index } \\
\hline & \multicolumn{2}{|c|}{$\begin{array}{l}\text { Mental Health Severity } \\
(0-10)\end{array}$} & \multicolumn{2}{|c|}{ Likely PsychologicalProblem (0/1) } \\
\hline & (1) & $(2)$ & (3) & (4) \\
\hline $\begin{array}{l}\text { Marginal Effect } \\
\text { (SE) }\end{array}$ & $\begin{array}{l}-0.179 * * \\
(0.068)\end{array}$ & $\begin{array}{l}-0.185^{* *} \\
(0.084)\end{array}$ & $\begin{array}{l}-0.014 * * \\
(0.006)\end{array}$ & $\begin{array}{l}-0.014 * \\
(0.007)\end{array}$ \\
\hline Mean of DV & 1.71 & 1.71 & 0.041 & 0.041 \\
\hline $\begin{array}{l}\text { Relative Effect of 1-SD } \\
\text { improvement in } \\
\text { economic conditions }\end{array}$ & $-2.0 \%$ & $-2.1 \%$ & $-6.4 \%$ & $-6.4 \%$ \\
\hline Sample size & 94,229 & 94,229 & 94,229 & 94,229 \\
\hline $\begin{array}{l}\text { Area-specific linear } \\
\text { time trends }\end{array}$ & No & Yes & No & Yes \\
\hline
\end{tabular}

Note: Results are from OLS (Columns 1-2) and probit (Columns 3-4) models with robust standard errors clustered on the state. SDQ is the Strengths and Difficulties Scale, which ranges from 0 to 10, and was coded so that higher scores reflect worse mental health. Covariates include age, sex, race/ethnicity, parental education, parental age, and parental marital status. Models include a full set of state fixed effects and time fixed effects. ${ }^{*} \mathrm{p}$-value $<.10$, ${ }^{*}$ p-value $<.05$, $* * * \mathrm{p}$-value $<.01$. 
Mental Health Severity (0-3) L Likely Psychological Problem $(0 / 1)$

\begin{tabular}{|c|c|c|c|c|}
\hline & \\
\hline & (1) & (2) & (3) & (4) \\
\hline $\begin{array}{l}\text { Marginal Effect } \\
\text { (SE) }\end{array}$ & $\begin{array}{l}0.0084^{* *} \\
(0.0035)\end{array}$ & $\begin{array}{c}0.0082 \\
(0.0053)\end{array}$ & $\begin{array}{l}0.0035^{* * *} \\
(0.0011)\end{array}$ & $\begin{array}{l}0.0053 * * * \\
(0.0016)\end{array}$ \\
\hline Mean of DV & 0.263 & 0.263 & 0.051 & 0.051 \\
\hline \multirow{4}{*}{$\begin{array}{l}\text { Relative Effect of 1-SD } \\
\text { improvement in } \\
\text { economic conditions }\end{array}$} & $-4.8 \%$ & $-4.8 \%$ & $-10.4 \%$ & $-15.7 \%$ \\
\hline & \multicolumn{4}{|c|}{$\underline{\text { Panel B. State Housing Price Index }}$} \\
\hline & \multicolumn{2}{|c|}{ Mental Health Severity (0-3) } & \multicolumn{2}{|c|}{$\begin{array}{l}\text { Likely Psychological Problem } \\
\qquad(0 / 1)\end{array}$} \\
\hline & (1) & (2) & (3) & (4) \\
\hline $\begin{array}{l}\text { Marginal Effect } \\
\text { (SE) }\end{array}$ & $\begin{array}{l}-0.065^{* * *} \\
(0.015)\end{array}$ & $\begin{array}{l}-0.061^{* * *} \\
(0.019)\end{array}$ & $\begin{array}{l}-0.020 * * * \\
(0.005)\end{array}$ & $\begin{array}{l}-0.024 * * * \\
(0.007)\end{array}$ \\
\hline Mean of DV & 0.263 & 0.263 & 0.051 & 0.051 \\
\hline $\begin{array}{l}\text { Relative Effect of 1-SD } \\
\text { improvement in } \\
\text { economic conditions }\end{array}$ & $-4.7 \%$ & $-4.4 \%$ & $-7.4 \%$ & $-8.9 \%$ \\
\hline Sample size & 110,267 & 110,267 & 110,267 & 110,267 \\
\hline $\begin{array}{l}\text { Area-specific linear } \\
\text { time trends }\end{array}$ & No & Yes & No & Yes \\
\hline
\end{tabular}

Note: Results are from OLS (Columns 1-2) and probit (Columns 3-4) models with robust standard errors clustered on the state. The Emotional Difficulty score ranges from 0 to 3, and was coded so that higher scores reflect worse mental health. Covariates include age, sex, race/ethnicity, parental education, parental age, and parental marital status. Models include a full set of state fixed effects and time fixed effects. ${ }^{*}$ p-value $<.10,{ }^{* *}$ p-value $<.05$, ${ }^{* * *}$-value $<.01$. 
Table 4. Outcomes Based on SDQ Scale - Heterogeneous Effects by Sex and Age

$\underline{\text { Panel A. State Unemployment Rates }}$

\begin{tabular}{lcccccccc} 
& \multicolumn{3}{c}{ Mental Health Severity (0-10) } & \multicolumn{3}{c}{ Likely Psychological Problem (0/1) } \\
\cline { 2 - 8 } & Males & Females & Age 4-11 & Age 12-17 & Males & Females & Age 4-11 & Age 12-17 \\
\cline { 2 - 8 } Marginal Effect & $0.032^{*}$ & 0.021 & $0.029^{*}$ & 0.026 & 0.0013 & $0.0045^{* *}$ & $0.0025^{* *}$ & $0.0042^{*}$ \\
$(\mathrm{SE})$ & $(0.018)$ & $(0.017)$ & $(0.017)$ & $(0.018)$ & $(0.0021)$ & $(0.0018)$ & $(0.0011)$ & $(0.0021)$ \\
Mean of DV & 1.83 & 1.60 & 1.62 & 1.84 & 0.046 & 0.036 & 0.035 & 0.049 \\
$\begin{array}{l}\text { Relative Effect of 1-SD } \\
\text { improvement in }\end{array}$ & $-2.6 \%$ & $-2.0 \%$ & $-2.7 \%$ & $-2.1 \%$ & $-4.3 \%$ & $-18.9 \%$ & $-10.8 \%$ & $-12.9 \%$ \\
economic conditions & & & & & & & &
\end{tabular}

Panel B. State Housing Price Index

\begin{tabular}{cccccccc}
\multicolumn{3}{c}{ Mental Health Severity (0-10) } & \multicolumn{3}{c}{ Likely Psychological Problem (0/1) } \\
\hline Males & Females & Age 4-11 & Age 12-17 & Males & Females & Age 4-11 & Age 12-17 \\
\hline$-0.173^{* *}$ & $-0.183^{* *}$ & -0.093 & $-0.302^{* * *}$ & -0.011 & $-0.018^{* *}$ & -0.004 & $-0.029^{* * *}$ \\
$(0.074)$ & $(0.084)$ & $(0.080)$ & $(0.086)$ & $(0.010)$ & $(0.008)$ & $(0.006)$ & $(0.010)$ \\
1.83 & 1.60 & 1.62 & 1.84 & 0.046 & 0.036 & 0.035 & 0.049 \\
$-1.8 \%$ & $-2.2 \%$ & $-1.1 \%$ & $-3.1 \%$ & $-4.5 \%$ & $-9.5 \%$ & $-2.2 \%$ & $-11.2 \%$ \\
& & & & & & & \\
\hline & & & & & & & \\
48,571 & 45,658 & 51,372 & 42,857 & 48,571 & 45,552 & 51,372 & 461
\end{tabular}

Marginal Effect

(SE)

Mean of DV

Relative Effect of 1-SD

improvement in

economic conditions

Sample size

48,571

(1)

bust standar

errors clust

Note: Results are from OLS and probit models with robust standard errors clustered on the state. SDQ is the Strengths and Difficul
Scale, which ranges from 0 to 10, and was coded so that higher scores reflect worse mental health. Covariates include age, sex, race/ethnicity, parental education, parental age, and parental marital status. Models include a full set of state fixed effects and time fixed effects. ${ }^{*}$ p-value $<.10,{ }^{* *}$ p-value $<.05, * * *$ p-value $<.01$. 
Table 5. Outcomes Based On Emotional Difficulty Score - Heterogeneous Effects by Sex and Age

Panel A. State Unemployment Rate

\begin{tabular}{|c|c|c|c|c|c|c|c|c|}
\hline & \multicolumn{8}{|c|}{ Panel A. State Unemployment Rate } \\
\hline & \multicolumn{4}{|c|}{ Mental Health Severity (0-3) } & \multicolumn{4}{|c|}{ Likely Psychological Problem (0/1) } \\
\hline & Males & Females & Age 4-11 & Age 12-17 & Males & Females & Age 4-11 & Age 12-17 \\
\hline $\begin{array}{l}\text { Marginal Effect } \\
\text { (SE) }\end{array}$ & $\begin{array}{c}0.010^{*} \\
(0.006)\end{array}$ & $\begin{array}{c}0.006^{*} \\
(0.065)\end{array}$ & $\begin{array}{l}0.010^{* *} \\
(0.004)\end{array}$ & $\begin{array}{c}0.008 \\
(0.006)\end{array}$ & $\begin{array}{l}0.0039 * * \\
(0.0019)\end{array}$ & $\begin{array}{l}0.0030 * * \\
(0.0013)\end{array}$ & $\begin{array}{l}0.0037^{* * *} \\
(0.0012)\end{array}$ & $\begin{array}{c}0.0036^{*} \\
(0.0019)\end{array}$ \\
\hline Mean of DV & 0.313 & 0.212 & 0.249 & 0.283 & 0.064 & 0.038 & 0.046 & 0.058 \\
\hline \multirow{4}{*}{$\begin{array}{l}\text { Relative Effect of 1- } \\
\text { SD improvement in } \\
\text { economic conditions }\end{array}$} & $-4.8 \%$ & $-4.3 \%$ & $-6.1 \%$ & $-4.3 \%$ & $-9.2 \%$ & $-11.9 \%$ & $-12.1 \%$ & $-9.4 \%$ \\
\hline & \multicolumn{8}{|c|}{ Panel B. State Housing Price Index } \\
\hline & \multicolumn{4}{|c|}{ Mental Health Severity (0-3) } & \multicolumn{4}{|c|}{ Likely Psychological Problem (0/1) } \\
\hline & Males & Females & Age 4-11 & Age 12-17 & Males & Females & Age 4-11 & Age 12-17 \\
\hline $\begin{array}{l}\text { Marginal Effect } \\
\text { (SE) }\end{array}$ & $\begin{array}{l}-0.072 * * * \\
(0.022)\end{array}$ & $\begin{array}{l}-0.056^{* * *} \\
(0.021)\end{array}$ & $\begin{array}{l}-0.046^{* * *} \\
(0.017)\end{array}$ & $\begin{array}{l}-0.090^{* * *} \\
(0.022)\end{array}$ & $\begin{array}{l}-0.023^{* *} \\
(0.009)\end{array}$ & $\begin{array}{l}-0.017^{* *} \\
(0.007)\end{array}$ & $\begin{array}{l}-0.014^{* *} \\
(0.005)\end{array}$ & $\begin{array}{l}-0.028^{* * *} \\
(0.009)\end{array}$ \\
\hline Mean of DV & 0.313 & 0.212 & 0.249 & 0.283 & 0.064 & 0.038 & 0.046 & 0.058 \\
\hline $\begin{array}{l}\text { Relative Effect of 1- } \\
\text { SD improvement in } \\
\text { economic conditions }\end{array}$ & $-4.4 \%$ & $-5.0 \%$ & $-3.5 \%$ & $-6.0 \%$ & $-6.8 \%$ & $-8.5 \%$ & $-5.8 \%$ & $-9.2 \%$ \\
\hline Sample size & 56,752 & 53,515 & 59,943 & 50,324 & 56,752 & 53,351 & 59,943 & 50,324 \\
\hline
\end{tabular}


Table 6. Marginal Effects of State-Level Economic Condition on Joint Distribution of Child and Parent Likely Psychological Problems within a Family

\begin{tabular}{lcc}
\hline $\begin{array}{l}\text { Joint distribution of child and } \\
\text { parent mental health }\end{array}$ & $\begin{array}{c}\text { Marginal Effect of One-Unit } \\
\text { Increase in State } \\
\text { Unemployment Rate }\end{array}$ & $\begin{array}{c}\text { Marginal Effect of One- } \\
\text { Unit Increase in State } \\
\text { HPI }\end{array}$ \\
\hline (Neither poor mental health) & $-0.0029^{*}$ & $0.0222^{* *}$ \\
& $(0.0015)$ & $(0.0083)$ \\
(Child poor mental health) & $0.0018^{*}$ & -0.0079 \\
& $(0.0011)$ & $(0.0065)$ \\
(Parent poor mental health) & 0.0007 & $-0.0112^{* * *}$ \\
& $(0.0009)$ & $(0.0035)$ \\
(Both poor mental health) & $0.0004^{*}$ & $-0.0031^{* * *}$ \\
& $(0.0002)$ & $(0.0011)$ \\
\hline
\end{tabular}

Note: Results are from a bivariate probit model. Child mental health is a binary indicator of Serious Psychological Problem based on the SDQ, Parent mental health is a binary indicator of severe psychological distress based on the K6 (3\% of parents have severe psychological distress). Marginal effects for the four categories sum to zero. Covariates include age, sex, race/ethnicity, parental education, parental age, and parental marital status. Models include a full set of state fixed effects and time fixed effects.

${ }^{*} \mathrm{p}$-value $<.10,{ }^{* *} \mathrm{p}$-value $<.05,{ }^{* * *} \mathrm{p}$-value $<.01$. 
Table 7. Probit Models of Special Education or Early Intervention Services for Emotional or Behavioral Problems

\begin{tabular}{|c|c|c|}
\hline & \multicolumn{2}{|c|}{ Panel A. Effects of State Unemployment Rate } \\
\hline & 1. & 2. \\
\hline $\begin{array}{l}\text { Marginal Effect } \\
\text { (SE) }\end{array}$ & $\begin{array}{l}0.00091^{* *} \\
(0.0004)\end{array}$ & $\begin{aligned} 0.00113^{*} \\
(0.00058)\end{aligned}$ \\
\hline Mean of DV & 0.024 & 0.024 \\
\hline \multirow{3}{*}{$\begin{array}{l}\text { Relative Effect of 1-SD improvement } \\
\text { in economic conditions }\end{array}$} & $-5.7 \%$ & $-7.1 \%$ \\
\hline & \multicolumn{2}{|c|}{ Panel B. Effects of State Housing Price Index } \\
\hline & 1. & 2. \\
\hline $\begin{array}{l}\text { Marginal Effect } \\
\text { (SE) }\end{array}$ & $\begin{array}{l}-0.0041^{*} \\
(0.0023)\end{array}$ & $\begin{array}{l}-0.0015 \\
(0.0024)\end{array}$ \\
\hline Mean of DV & 0.024 & 0.024 \\
\hline $\begin{array}{l}\text { Relative Effect of 1-SD improvement } \\
\text { in economic conditions }\end{array}$ & $-3.2 \%$ & $1.2 \%$ \\
\hline Sample size & 240,006 & 240,006 \\
\hline Area-Specific Linear Time Trends & No & Yes \\
\hline
\end{tabular}

Note: Results are from probit models with robust standard errors clustered on the state.

Covariates include age, sex, race/ethnicity, parental education, parental age, and parental marital status. Models include a full set of state fixed effects and time fixed effects.

${ }^{*}$ p-value $<.10,{ }^{* *}$ p-value $<.05,{ }^{* * *}$ p-value $<.01$. 
Table 8. Probability of Likely Psychological Problem, based on SDQ Scale - Heterogeneous Effects by Household Education. Race/Ethnicity, and Parental Employment

Panel A. State-level Unemployment

\begin{tabular}{|c|c|c|c|c|c|c|}
\hline & $\begin{array}{l}\text { 1. Less than } \\
\text { College Degree }\end{array}$ & $\begin{array}{l}\text { 2. At least } \\
\text { College Degree }\end{array}$ & 3. White & $\begin{array}{l}\text { 4. Non- } \\
\text { white }\end{array}$ & $\begin{array}{l}\text { 5. Both Parents } \\
\text { Working }\end{array}$ & $\begin{array}{c}\text { 6. At least } 1 \\
\text { unemployed parent }\end{array}$ \\
\hline $\begin{array}{l}\text { Marginal Effect } \\
\text { (SE) }\end{array}$ & $\begin{array}{l}0.003 * * \\
(0.002)\end{array}$ & $\begin{array}{c}0.003 \\
(0.002)\end{array}$ & $\begin{array}{l}0.004^{* *} \\
(0.002)\end{array}$ & $\begin{array}{l}0.003^{* *} \\
(0.001)\end{array}$ & $\begin{array}{c}0.001 \\
(0.001)\end{array}$ & $\begin{array}{c}0.006 \\
(0.004)\end{array}$ \\
\hline Mean of DV & 0.050 & 0.024 & 0.042 & 0.039 & 0.027 & 0.055 \\
\hline $\begin{array}{l}\text { Relative Effect of 1- } \\
\text { SD improvement in } \\
\text { economic conditions }\end{array}$ & $-9.1 \%$ & $-18.9 \%$ & $-13.3 \%$ & $-11.6 \%$ & $-5.6 \%$ & $-16.5 \%$ \\
\hline
\end{tabular}

\begin{tabular}{|c|c|c|c|c|c|c|}
\hline & \multicolumn{6}{|c|}{ Panel B. State-level HPI } \\
\hline & $\begin{array}{l}\text { 1. Less than } \\
\text { College Degree }\end{array}$ & $\begin{array}{l}\text { 2. At least } \\
\text { College Degree }\end{array}$ & 3. White & $\begin{array}{l}\text { 4. Non- } \\
\text { white }\end{array}$ & $\begin{array}{l}\text { 5. Both Parents } \\
\text { Working }\end{array}$ & $\begin{array}{c}\text { 6. At least } 1 \\
\text { unemployed parent }\end{array}$ \\
\hline $\begin{array}{l}\text { Marginal Effect } \\
\text { (SE) }\end{array}$ & $\begin{array}{l}-0.020 * * \\
(0.008)\end{array}$ & $\begin{array}{l}-0.004 \\
(0.007)\end{array}$ & $\begin{array}{l}-0.014 * \\
(0.007)\end{array}$ & $\begin{array}{l}-0.014 \\
(0.010)\end{array}$ & $\begin{array}{l}-0.006 \\
(0.008)\end{array}$ & $\begin{array}{l}-0.012 \\
(0.027)\end{array}$ \\
\hline Mean of DV & 0.050 & 0.024 & 0.042 & 0.039 & 0.027 & 0.055 \\
\hline $\begin{array}{l}\text { Relative Effect of 1- } \\
\text { SD improvement in } \\
\text { economic conditions }\end{array}$ & $-7.6 \%$ & $-3.2 \%$ & $-6.3 \%$ & $-6.8 \%$ & $-4.2 \%$ & $-4.1 \%$ \\
\hline Sample size & 65,563 & 28,564 & 46,990 & 47,219 & 39,300 & 6,335 \\
\hline
\end{tabular}

Note: Results are from probit models with robust standard errors clustered on the state. SDQ is the Strengths and Difficulties Scale. Covariates include age, sex, race/ethnicity, parental education, parental age, and parental marital status. Models include a full set of state fixed effects and time fixed effects.

${ }^{*}$ p-value $<.10,{ }^{* *}$ p-value $<.05,{ }^{* * *}$ p-value $<.01$. 
Table 9. Probability of Likely Psychological Problem, based on Emotional Difficulty Score - Heterogeneous Effects by Household Education. Race/Ethnicity, and Parental Employment

\begin{tabular}{|c|c|c|c|c|c|c|}
\hline & \multicolumn{6}{|c|}{ Panel A. State Unemployment Rate } \\
\hline & $\begin{array}{l}\text { 1. Less than } \\
\text { College Degree }\end{array}$ & $\begin{array}{l}\text { 2. At least } \\
\text { College Degree }\end{array}$ & 3. White & $\begin{array}{l}\text { 4. Non- } \\
\text { white }\end{array}$ & $\begin{array}{l}\text { 5. Both Parents } \\
\text { Working }\end{array}$ & $\begin{array}{c}\text { 6. At least } 1 \\
\text { unemployed parent }\end{array}$ \\
\hline $\begin{array}{l}\text { Marginal Effect } \\
\text { (SE) }\end{array}$ & $\begin{array}{l}0.0043^{* * *} \\
(0.0014)\end{array}$ & $\begin{array}{c}0.0018 \\
(0.0015)\end{array}$ & $\begin{array}{c}0.0025 \\
(0.0016)\end{array}$ & $\begin{array}{l}0.0049^{* * *} \\
(0.0011)\end{array}$ & $\begin{array}{c}0.0017 \\
(0.0014)\end{array}$ & $\begin{array}{c}0.0012 \\
(0.0044)\end{array}$ \\
\hline Mean of DV & 0.058 & 0.038 & 0.056 & 0.044 & 0.035 & 0.077 \\
\hline $\begin{array}{l}\text { Relative Effect of 1- } \\
\text { SD improvement in } \\
\text { economic conditions }\end{array}$ & $-11.2 \%$ & $-7.2 \%$ & $-6.7 \%$ & $-16.8 \%$ & $-7.3 \%$ & $-2.4 \%$ \\
\hline
\end{tabular}

Panel B. State Housing Price Index

\begin{tabular}{lcccccc} 
& $\begin{array}{c}\text { 1. Less than } \\
\text { College Degree }\end{array}$ & $\begin{array}{c}\text { 2. At least } \\
\text { College Degree }\end{array}$ & 3. White & $\begin{array}{c}\text { 4. Non- } \\
\text { white }\end{array}$ & $\begin{array}{c}\text { 5. Both Parents } \\
\text { Working }\end{array}$ & $\begin{array}{c}\text { 6. At least 1 } \\
\text { unemployed parent }\end{array}$ \\
\cline { 2 - 7 } $\begin{array}{l}\text { Marginal Effect } \\
\text { (SE) }\end{array}$ & $-0.023^{* * *}$ & -0.013 & $-0.017^{*}$ & $-0.019 * *$ & -0.0088 & $-0.0385^{*}$ \\
$(0.007)$ & $(0.009)$ & $(0.009)$ & $(0.009)$ & $(0.0074)$ & $0.0219)$ \\
Mean of DV & 0.058 & 0.038 & 0.056 & 0.044 & -0.035 & $-9.8 \%$ \\
Relative Effect of 1- & $-7.5 \%$ & $-6.5 \%$ & $-5.8 \%$ & $-8.2 \%$ & & $-9.5 \%$ \\
$\begin{array}{l}\text { SD improvement in } \\
\text { economic conditions }\end{array}$ & & & & & 36,460 & 40,028
\end{tabular}

Note: Results are from probit models with robust standard errors clustered on the MSA. Covariates include age, sex, race/ethnicity, parental education, parental age, and parental marital status. Models include a full set of state fixed effects and time fixed effects. ${ }^{*}$ p-value $<.10,{ }^{* *}$ p-value $<.05, * * *$ p-value $<.01$. 
Table 10. Effects of Unemployment Rate on Health and Economic Outcomes, by Household Predicted Employment

(1)

Bottom quintile of predicted employment
(2)

Three middle quintiles of predicted employment
(3)

Top quintile of predicted employment

Panel A. Outcome $=$ Whether Any Parent is Unemployed and Looking for Work

\begin{tabular}{lccc} 
Marginal Effect & $0.0155^{* * *}$ & $0.0117^{* * *}$ & 0.0025 \\
\cline { 2 - 4 } (SE) & $(0.0028)$ & $(0.0019)$ & $(0.0018)$ \\
Mean of DV & 0.106 & 0.069 & 0.034 \\
Sample size & 20,678 & 69,703 & 20,726 \\
\cline { 2 - 4 } & \multicolumn{3}{c}{ Panel B. Outcome = Family Income (\$) } \\
\cline { 2 - 4 } Marginal Effect & $-692.21^{* *}$ & $-1,454.19^{* * *}$ & $-2,559.84^{* *}$ \\
(SE) & $(327.64)$ & $(431.96)$ & $(1,109.03)$ \\
Mean of DV & $\$ 32,256$ & $\$ 66,154$ & $\$ 108,887$ \\
Sample size & 20,678 & 69,703 & 20,726 \\
\cline { 2 - 4 } & Panel C. Outcome $=$ Likely Psychological Problem (based on SDQ) \\
\cline { 2 - 4 } Marginal Effect & -0.0011 & $0.0037^{* *}$ & $0.0034^{*}$ \\
(SE) & $(0.002)$ & $(0.0017)$ & $(0.0019)$ \\
Mean of DV & 0.053 & 0.043 & 0.029 \\
Sample size & 17,402 & 58,946 & 17,626 \\
\cline { 2 - 4 } & $\underline{\text { Panel D. Outcome = Likely Psychological Problem (based on Emotional }}$ \\
\cline { 2 - 4 } & \multicolumn{3}{c}{ Difficulty score) } \\
Marginal Effect & $0.0070^{* * *}$ & $0.0026^{*}$ & $0.0027^{*}$ \\
(SE) & $(0.0024)$ & $(0.0013)$ & $0.0016)$ \\
Mean of DV & 0.053 & 0.054 & 20,533 \\
Sample size & 20,410 & 68,987 & 0.042 \\
\hline
\end{tabular}

Note: Results in Panels A-B are from OLS models, and results in Panels C-D are from Probit models. Robust standard errors are clustered on the state. SDQ is the Strengths and Difficulties Scale. Covariates include age, sex, race/ethnicity, parental education, parental age, and parental marital status. Models include a full set of state fixed effects and time fixed effects. Household predicted employment is described in the text. ${ }^{*}$-value $<.10,{ }^{* *} \mathrm{p}$-value $<.05,{ }^{* * *} \mathrm{p}$-value $<.01$. 
Appendix Table 1. Comparing Independent Effects of Unemployment Rates and HPI with Effects from separate models of, SDQ Outcomes

\begin{tabular}{|c|c|c|c|c|c|c|c|c|}
\hline & \multicolumn{4}{|c|}{ OLS: Mental Health Severity (0-10) } & \multicolumn{4}{|c|}{ Probit: Likely Psychological Problem (0/1) } \\
\hline & $\begin{array}{c}\text { (1a) } \\
\text { Separate } \\
\text { Models }\end{array}$ & $\begin{array}{c}\text { (1b) } \\
\text { Single } \\
\text { Model }\end{array}$ & $\begin{array}{c}\text { (2a) } \\
\text { Separate } \\
\text { Models }\end{array}$ & $\begin{array}{c}\text { (2b) } \\
\text { Single } \\
\text { Model }\end{array}$ & $\begin{array}{c}\text { (3a) } \\
\text { Separate } \\
\text { Models }\end{array}$ & $\begin{array}{l}\text { (3b) } \\
\text { Single } \\
\text { Model }\end{array}$ & $\begin{array}{l}\quad(4 a) \\
\text { Separate } \\
\text { Models }\end{array}$ & $\begin{array}{l}(4 b) \\
\text { Single } \\
\text { Model }\end{array}$ \\
\hline & & & $\underline{\text { Panel } A}$ & State-LeI & l Unemplo & ment & & \\
\hline \multirow[t]{2}{*}{$\begin{array}{l}\text { Marginal Effect } \\
\text { (SE) }\end{array}$} & $\begin{array}{r}0.0263 * \\
(0.0132)\end{array}$ & $\begin{array}{c}0.0095 \\
(0.0178)\end{array}$ & $\begin{array}{l}0.0434 * * \\
(0.0163)\end{array}$ & $\begin{array}{c}0.0273 \\
(0.0236)\end{array}$ & $\begin{array}{l}0.0030 * * \\
(0.0012)\end{array}$ & $\begin{array}{c}0.0021 \\
(0.0016)\end{array}$ & $\begin{array}{l}0.0037 * * * \\
(0.0014)\end{array}$ & $\begin{array}{c}0.0029 \\
(0.0020)\end{array}$ \\
\hline & \multicolumn{8}{|c|}{ Panel B. State-Level HPI } \\
\hline $\begin{array}{l}\text { Marginal Effect } \\
(\mathrm{SE})\end{array}$ & $\begin{array}{l}-0.179 * * \\
(0.068)\end{array}$ & $\begin{array}{l}-0.150 \\
(0.091)\end{array}$ & $\begin{array}{c}-0.185^{* *} \\
(0.084)\end{array}$ & $\begin{array}{l}-0.115 \\
(0.121)\end{array}$ & $\begin{array}{l}-0.014^{* *} \\
(0.006)\end{array}$ & $\begin{array}{l}-0.0080 \\
(0.0080)\end{array}$ & $\begin{array}{l}-0.014^{*} \\
(0.007)\end{array}$ & $\begin{array}{l}-0.0065 \\
(0.0097)\end{array}$ \\
\hline Sample size & \multicolumn{2}{|c|}{94,229} & \multicolumn{2}{|c|}{94,229} & \multicolumn{2}{|c|}{94,229} & \multicolumn{2}{|c|}{94,229} \\
\hline $\begin{array}{l}\text { Area-specific linear time } \\
\text { trends }\end{array}$ & No & No & Yes & Yes & No & No & Yes & Yes \\
\hline
\end{tabular}

Note: Results are from OLS and probit models with robust standard errors clustered on the state. SDQ is the Strengths and Difficulties Scale, which ranges from 0 to 10 , and was coded so that higher scores reflect worse mental health. Covariates include age, sex, race/ethnicity, parental education, parental age, and parental marital status. Models include a full set of state fixed effects and time fixed effects.

${ }^{*}$ p-value $<.10, * *$ p-value $<.05, * * *$ p-value $<.01$. 
Appendix Table 2. Comparing Independent Effects of Unemployment Rates and HPI with Effects from Separate Models, Outcomes Based on Emotional Difficulty Score

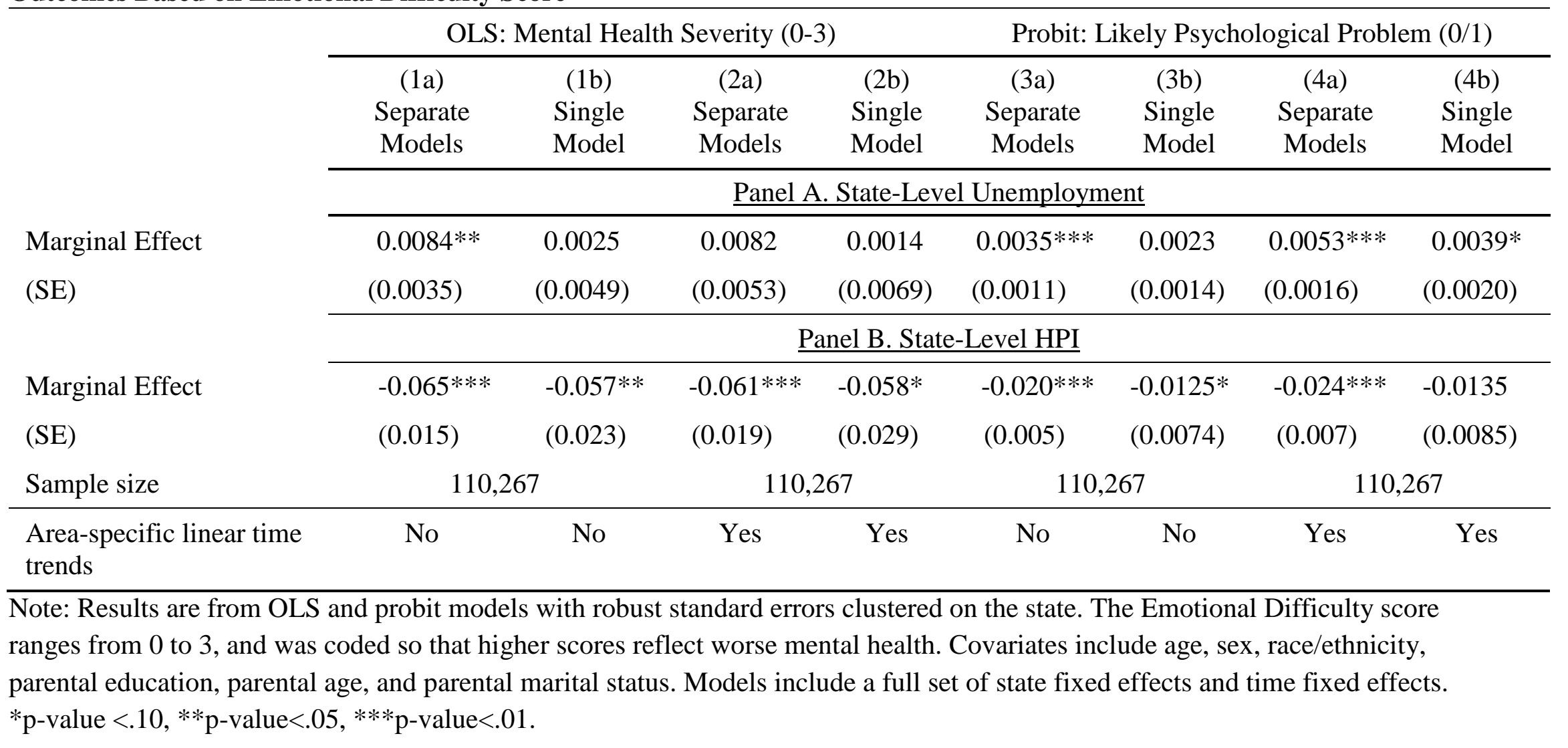




\begin{tabular}{|c|c|c|c|}
\hline & $\begin{array}{l}\text { (1) } \\
\text { Top quintile of } \\
\text { predicted } \\
\text { unemployment }\end{array}$ & $\begin{array}{c}\text { (2) } \\
\text { Three middle } \\
\text { quintiles of predicted } \\
\text { unemployment }\end{array}$ & $\begin{array}{l}\text { (3) } \\
\text { Bottom quintile of } \\
\text { predicted } \\
\text { unemployment }\end{array}$ \\
\hline & \multicolumn{3}{|c|}{$\underline{\text { Panel A. Outcome = Likely Psychological Problem (based on SDQ) }}$} \\
\hline $\begin{array}{l}\text { Marginal Effect } \\
\text { (SE) }\end{array}$ & $\begin{array}{l}-0.0010 \\
(0.0030)\end{array}$ & $\begin{array}{c}0.0027 \\
(0.0016)\end{array}$ & $\begin{array}{l}0.0052^{* * *} \\
(0.0017)\end{array}$ \\
\hline Mean of DV & 0.063 & 0.041 & 0.027 \\
\hline \multirow[t]{2}{*}{ Sample size } & 17,834 & 55,558 & 20,450 \\
\hline & \multicolumn{3}{|c|}{$\frac{\text { Panel B. Outcome }=\text { Likely Psychological Problem (based on }}{\text { Emotional Difficulties) }}$} \\
\hline $\begin{array}{l}\text { Marginal Effect } \\
\text { (SE) }\end{array}$ & $\begin{array}{c}0.0045^{*} \\
(0.0024)\end{array}$ & $\begin{array}{l}0.0034^{* *} \\
(0.0014)\end{array}$ & $\begin{array}{c}0.0021 \\
(0.0021)\end{array}$ \\
\hline Mean of DV & 0.072 & 0.049 & 0.043 \\
\hline \multirow[t]{2}{*}{ Sample size } & 21,007 & 64,779 & 24,135 \\
\hline & \multicolumn{3}{|c|}{$\frac{\text { Panel C. Outcome }=\text { Whether Any Parent in Labor Force but }}{\text { Unemployed }}$} \\
\hline $\begin{array}{l}\text { Marginal Effect } \\
\text { (SE) }\end{array}$ & $\begin{array}{l}0.0144^{* * *} \\
(0.0037)\end{array}$ & $\begin{array}{l}0.0113^{* * *} \\
(0.0018)\end{array}$ & $\begin{array}{l}0.0052 * * * \\
(0.0019)\end{array}$ \\
\hline Mean of DV & 0.119 & 0.065 & 0.035 \\
\hline \multirow[t]{2}{*}{ Sample size } & 21,336 & 65,410 & 24,361 \\
\hline & \multicolumn{3}{|c|}{$\underline{\text { Panel D. Outcome }=\text { Family Income }}$} \\
\hline $\begin{array}{l}\text { Marginal Effect } \\
\text { (SE) }\end{array}$ & $\begin{array}{c}37.34 \\
(508.89)\end{array}$ & $\begin{array}{l}-1,644.04^{* * *} \\
(389.30)\end{array}$ & $\begin{array}{l}-2,528.02 * * \\
(1,098.56)\end{array}$ \\
\hline Mean of DV & 28,913 & $\$ 62,593$ & $\$ 119,343$ \\
\hline Sample size & 21,336 & 65,410 & 24,361 \\
\hline
\end{tabular}

Note: Results are from probit (panel A and B) and OLS (panel C and D) models with robust standard errors clustered on the state. SDQ is the Strengths and Difficulties Scale. Covariates include age, sex, race/ethnicity, parental education, parental age, and parental marital status. Models include a full set of area fixed effects and time fixed effects. Household predicted unemployment is predicted from the 2001 NHIS data, as described in the text. *p-value $<.10$, ${ }^{* *}$ p-value $<.05,{ }^{* * *}$ p-value $<.01$. 